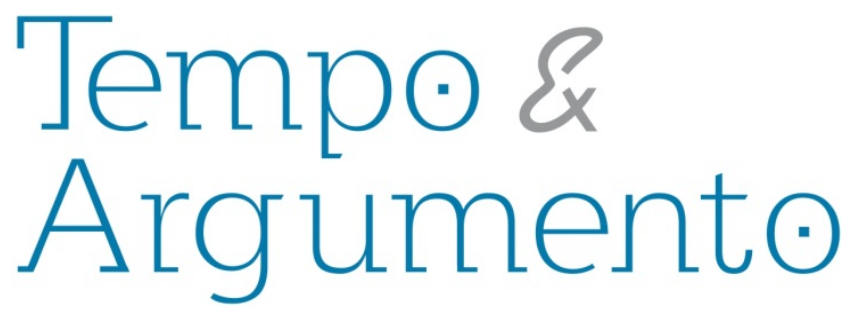

\title{
El Frente Antifascista y la Política Militar del Partido Comunista de Chile bajo dictadura, 1973-1980 ${ }^{1}$
}

\begin{abstract}
Resumen
Este artículo indaga la trayectoria de la política militar del Partido Comunista de Chile, particularmente bajo su apuesta política de Frente Antifascista (1973-1980). Al respecto, sostenemos que, en una primera etapa, este partido desarrolló su política militar fundamentalmente en base a las evaluaciones realizadas sobre las causas de la derrota de Allende. Lo anterior implicó una continuidad casi irrestricta de su política militar durante los primeros años de dictadura. No obstante, a partir de las primeras medidas tomadas en función de palear las deficiencias de ésta, así como también frente el inminente alargue e institucionalización de la dictadura, se produjo una lenta pero significativa ampliación de su política militar a fines de los 1970, dinámica que terminó contribuyendo tanto a la reconfiguración política de su militancia como a su apuesta para terminar con la dictadura.
\end{abstract}

Palabras clave: Dictadura; Comunismo; Política Militar; Violencia Política, Chile.

\section{Claudio Pérez Silva}

Profesor Doctor en la Escuela de Historia, Universidad Academia de Humanismo Cristiano, y del Departamento de Historia, Universidad de Santiago de Chile. claupere73@yahoo.com

\section{Para citar este artículo:}

PÉREZ SILVA, Claudio. El Frente Antifascista y la Política Militar del Partido Comunista de Chile bajo dictadura, 1973-1980. Tempo e Argumento, Florianópolis, v. 7, n.16, p. 154 - 182. set./dez. 2015.

\section{DOI: $10.5965 / 2175180307162015154$}

http://dx.doi.org/10.5965/21751803071652015154

\footnotetext{
${ }^{1}$ Este trabajo forma parte del proyecto de investigación FONDECYT 1130323, Contexto histórico y dinámicas políticas de la insurgencia armada en Chile (1978-1994).
} 


\section{Antifascist Front and military politics of the Communist Party of Chile under dictatorship, 1973-1980}

\begin{abstract}
This article inquires about the route of the military politics of the Communist Party of Chile, particularly under its political commitment to the Antifascist Front (1973-1980). In this regard, we argue that, in a first stage, this party pursued its military politics primarily based on evaluations about the causes of Allende's defeat. This implied an almost unrestricted continuity of its military politics during the early years of dictatorship. However, after the first measures taken in order to palliate its shortcomings, and also face the imminent extension and institutionalization of dictatorship, there was a slow, but significant expansion of its military politics in the late 1970s, a dynamics that ended up contributing both to the political reconfiguration of its militancy and its commitment to bring the dictatorship to an end.
\end{abstract}

Keywords: Dictatorship; Communism; Military Policy; Political Violence; Chile.

\section{A Frente Antifascista e a Política Militar do Partido Comunista do Chile durante a ditadura, 1973-1980}

\begin{abstract}
Resumo
Este artigo investiga a trajetória da política militar do Partido Comunista do Chile, particularmente durante sua aposta política de Frente Antifascista (1973-1980). Nesse sentido, sustentamos que, em uma primeira etapa, esse partido desenvolveu sua política militar fundamentalmente com base nas avaliações realizadas acerca das causas da derrota de Allende. Isso implicou uma continuidade quase irrestrita de sua política militar durante os primeiros anos da ditadura. Contudo, a partir das primeiras medidas adotadas para atenuar suas deficiências, assim como, também, diante do iminente prolongamento e institucionalização da ditadura, produziu-se uma lenta, mas significativa ampliação de sua política militar no final da década de 1970, dinâmica que acabou contribuindo tanto para a reconfiguração política de sua militância como com sua aposta para acabar com a ditadura.
\end{abstract}

Palavras-chave: Ditadura; Comunismo; Política Militar; Violência Política; Chile.

\section{Escenarios y dinámicas políticas de la dictadura chilena, 1973-1980}

El Golpe de Estado de septiembre de 1973 fue una intervención militar completa, pensada y materializada por el conjunto de las Fuerzas Armadas y de Orden con el objetivo de reconfigurar la sociedad chilena sobre nuevas concepciones sociales, políticas y económicas. Fue, por tanto, una refundación (GOICOVIC, 2006; GÁRATE, 2012). En función de dicho objetivo, la dictadura se articuló política, ideológica, social y militarmente a través de una amplia alianza de fuerzas - principalmente anticomunistas y bajo una lógica o concepción política represiva totalizante e integral enmarcada en los cánones de la Doctrina de Seguridad Nacional y la estrategia de contrainsurgencia. 
Dentro de estos marcos políticos, se llevó adelante la más amplia y contundente ofensiva represiva en contra de los principales referentes políticos de la izquierda chilena, así como de las distintas expresiones del movimiento popular chileno. Para ello, se implementó sistemáticamente un tipo particular de represión que escapaba a los tradicionales mecanismos y formas represivas con las cuales el Estado, las clases dominantes y las fuerzas de seguridad, en distintas etapas de la historia de Chile, habían enfrentado el protagonismo y las diversas arremetidas político-sociales del movimiento popular y la izquierda chilena en la dinámica política nacional.

En este contexto, se da paso a la detención y desaparición de personas, así como a las ejecuciones de detenidos, al exilio masivo de miles de chilenos, la prisión política y tortura sistemática de los detenidos, la mayoría de ellos militantes de partidos de izquierda con fuerte peso en la clase trabajadora organizada, el mundo sindical campesino, el movimiento de pobladores y el estudiantil, garantizando de esta forma el aislamiento de las organizaciones políticas y su capacidad para reconstituirse al alero de las dinámicas del movimiento popular (GOICOVIC, 2006; ÁLVAREZ, 2003; PINTO, 2006). EI terror, expresado como terrorismo de Estado, fue entonces la forma preferente y uniforme para frenar todo intento de rearticulación política social o de resistencia a la dictadura (MOULIAN, 1997).

Una vez logrados estos objetivos, las condiciones políticas, sociales y militares para la refundación capitalista y la construcción de la nueva sociedad estaban garantizadas. Con esto, la dictadura llevó adelante la refundación de la sociedad y la economía chilena en torno a la matriz neoliberal. La nueva economía reforzó el carácter dependiente y exportador de materias primas, fomentando la inversión extranjera (aparte del cobre) en las áreas forestales, de pesca y agroindustrial. Se privatizaron las empresas del Estado y se privilegió la importación de manufacturas, ahogando y terminando con gran parte de la industria nacional (GÁRATE, 2012; TIRONI, 1988; CAMPERO, 1984).

Es en este marco histórico de cruenta represión a la izquierda chilena y al conjunto del movimiento popular, como también de profunda restructuración de la sociedad chilena, donde debemos inscribir las discusiones y la trayectoria de los lineamientos políticos desarrollados por el comunismo chileno para enfrentar a la dictadura. 


\section{El Partido Comunista de Chile y la Política del Frente Anti-Fascista}

Las primeras respuestas y líneas políticas levantadas por el Partido Comunista de Chile (PCCh) después del Golpe de Estado fueron dirigidas fundamentalmente en pos de la reanimación de la militancia comunista a objeto de conservar las diversas estructuras regionales y nacionales, así como también asegurar la unidad partidaria y su respectiva conducción política sobre el grueso de la militancia. Desde el punto de vista político, tanto en el interior como en el exilio, la apuesta fundamental de los comunistas chilenos se concentró en torno a las denuncias de las violaciones a los derechos humanos cometidas por la dictadura, el trabajo de solidaridad con los detenidos, así como también el situar a los militares golpistas chilenos como una Junta de carácter fascista, resaltando a partir de ello, el supuesto aislamiento político nacional e internacional en que se hallaba. Por otra parte, desde el punto de vista de su accionar y considerando para ello la tradicional centralidad que le asigna el PCCh a la clase trabajadora, los lineamientos y esfuerzos del PCCh se orientaron también a mantener los vínculos y las diversas expresiones organizativas del movimiento popular chileno donde los comunistas tenían una gran influencia, particularmente las del mundo sindical.

Lo apremiante de la realidad impuesta por la dictadura marcó los ritmos y fijó la dirección de las tareas y los objetivos a desarrollar en lo inmediato. El tiempo presente de la lucha contra la junta fascista encuadró todos los esfuerzos partidarios en torno a la búsqueda de formas y propuestas políticas a desarrollar, particularmente en el segmento de la militancia comunista que se encontraba en condiciones de clandestinidad y acosados por la represión en Chile. Este elemento de contexto es de suma importancia a la hora de analizar las características y los contornos de la política desarrollada por el PCCh inmediatamente después del Golpe de Estado. El escenario y las necesidades impuestas por la dictadura implicaron, entre otras cosas para la dirigencia comunista en Chile, la conservación en gran medida y sin mayores cuestionamientos de concepciones políticas y visiones históricas construidas en relación a la sociedad chilena.

En el mismo sentido, significó la persistencia de elementos programáticos y estratégicos, así como el reforzamiento de las lógicas de análisis y consideraciones de fuerzas para determinar las formas de lucha y su política de alianzas. En definitiva, 
condicionó y enmarcó la continuidad de las definiciones políticas respecto al carácter de la revolución chilena y las apuestas políticas desarrolladas por el PCCh hasta el triunfo electoral de la UP, incluso hasta el propio Golpe de Estado. En términos políticos, implicó que las nuevas lecturas desarrolladas por el PCCh en el marco de la lucha contra la dictadura tendieran a reforzar su propuesta de vía chilena al socialismo o sumar algunos elementos de análisis - como el carácter fascista de la Junta y peso del fascismo en una parte de la oficialidad chilena - más que a discutir la trayectoria política de este partido. Los elementos de tradición y continuidad se impusieron al cambio. Lo nuevo del análisis y la apuesta política, en este caso el Frente Antifascista, no implicó un cambio de timón teniendo en cuenta el descalabro producido por la derrota de la UP, sino más bien reforzamiento de los ritmos y la dirección del proyecto.

La dinámica partidaria anterior es posible identificar a través de la revisión y estudio de las primeras declaraciones y definiciones políticas alcanzadas por el PCCh respecto de la dictadura y la forma en cómo enfrentarla. De igual forma, a partir de las alusiones y los análisis políticos en los cuales se aborda la derrota de la Unidad Popular. Un elemento de continuidad es el llamado permanente a la unidad de la izquierda y la ampliación necesaria en el marco de las alianzas políticas para derrotar a la Junta Militar, particularmente, a la inclusión y trabajo en conjunto con el Partido Demócrata Cristiano. En este marco político de lucha, plantea el PCCh, tenían un lugar “cada hombre, mujer o joven de nuestro pueblo", no importaba si habían sido parte del entramado de la oposición a la Unidad Popular o si fueron confundidos "por la propaganda de los reaccionarios". Lo importante para los comunistas era que millones de chilenos habían "visto el fascismo cara a cara y están dispuestos a luchar contra él".2

A partir de estas formulaciones políticas, es posible identificar dos grandes elementos que se mantuvieron presentes en el discurso y en las apuestas del PCCh durante la dictadura. Por una parte, "el Ilamado a la unidad más amplia (típicamente 'frentepopulista') y, por otro, el énfasis de la unidad en la base, más allá de que la Directiva democratacristiana se negara a un acuerdo formal con el PCCh..." (ÁLVAREZ, 2003). Y el otro elemento importante a destacar en estas primeras declaraciones dice relación con la problemática de las formas de lucha y el papel de las masas en ella. Lo

\footnotetext{
${ }^{2}$ La voz de orden es la unidad, Santiago, 11 de octubre de 1973, In: Desde Chile hablan los comunistas!, 32.
} 
fundamental, a nuestro juicio, es la centralidad que el PCCh le otorga a la lucha de masas en este contexto, deslizando con ello un distanciamiento claro con las posiciones que tempranamente levantara el Movimiento de Izquierda Revolucionaria (MIR) para enfrentar a la dictadura, particularmente en torno a las formas armadas de lucha. Frente a esto último, señalaban la importancia de poner "el acento en la organización, la unidad y la lucha de las masas y en el desarrollo creciente de su conciencia política". ${ }^{3}$

Plantean igualmente que mediante la movilización de las masas populares es posible poner término a la represión, el crimen y la propia dictadura. En conclusión, que "la lucha de masas conseguirá la victoria definitiva del pueblo en el trabajo creador consciente, en las aulas estudiantiles abiertas al diálogo fecundo y en la rebeldía de los jóvenes, en la paz y la tranquilidad de los hogares". “ Bajo esta concepción, la izquierda chilena debía buscar incesantemente la unidad con los más amplios sectores sociales y políticos, incluidas las capas medias, la burguesía y los sectores antifascistas de las FF. AA., que en conjunto tenían que llevar adelante las tareas de reconstrucción democrática.

De esta manera, a partir de las primeras reflexiones desarrolladas por la dirigencia comunista respecto a la experiencia de la Unidad Popular (UP), se establecía un importante puente político con los objetivos planteados en función del término de la dictadura: dando sentido, fundamento y continuidad, a dos grandes ejes temáticos: las formas de lucha y la política de alianzas. En cuanto a los balances relacionados con la derrota de Allende, el PCCh destaca entre los principales factores causantes de su descalabro el aislamiento de "la clase obrera". La situación anterior, a juicio del PCCh, habría provocado un cambio significativo y negativo en la correlación de fuerzas favorables a las transformaciones sociales, contexto utilizado hábilmente por los sectores golpistas para desencadenar su estrategia de derrocamiento de la Unidad Popular. En este marco, el PCCh establecía que tanto el carácter del Golpe de Estado como el de la propia dictadura (fascista), con sus lógicas y dinámicas represivas y antidemocráticas, así como también las negativas consecuencias que tenían sobre la mayoría de la población las políticas llevadas adelante por "la Junta", generaban las condiciones propicias para una amplia unidad política y social en contra de la Junta Militar.

\footnotetext{
${ }^{3}$ Ibíd. 27.

${ }^{4}$ Ibíd., 32.
} 
Bajo esta concepción, los “enemigos fundamentales del pueblo de Chile" continuaban siendo los sectores y grupos que habían materializado el Golpe de Estado y se beneficiaban también de las dinámicas y objetivos impuestos por la dictadura. Según los comunistas, estos sectores eran "los mismos del pasado: el imperialismo y la oligarquía monopolista y terrateniente". ${ }^{5}$ Esta definición inicial es ilustrativa en cuanto a lo que venimos planteando, ya que reforzaba las concepciones generales respecto del carácter de la revolución chilena y los enemigos fundamentales que había establecido este partido antes del Golpe de Estado y a partir de esto, daba continuidad a gran parte de las lógicas y maneras de como los comunistas concebían el desarrollo de su política.

En base a la lectura anterior, planteaban que se habían creado

[...] objetivamente, condiciones para un frente unitario muy amplio. En el terreno político esta situación reafirma la vigencia de la Unidad Popular como expresión unitaria del pueblo, pero, al mismo tiempo, impone ir más allá, a la acción común y la unidad con sectores del pueblo que no estuvieron con el Gobierno Popular. ${ }^{6}$

Lo importante de estas reflexiones es que fijan criterios y contenidos bajo los cuales debía articularse la política de alianzas del PCCh durante los años 1970. A partir de ella, se puede comprender, por un lado, la búsqueda permanente y central por desarrollar trabajo conjunto con la Democracia Cristina. Por otro, el distanciamiento y rechazo a la denominada ultraizquierda. Según el PCCh, el papel principal en la lucha contra la dictadura lo tenían las masas, expresado en capacidad de movilización y amplitud con todos los sectores democráticos, progresistas y antifascistas. Para el PCCh, toda actividad política ajena o desvinculada de las masas, de sus tradiciones y capacidades, no solamente eran un error, sino además, llamaban y daban justificación a las actividades y políticas represivas del fascismo sobre el amplio campo de los sectores democráticos antifascistas. De ahí que planteara abiertamente el rechazo a cualquier actividad política que insinuara el enfrentamiento armado a la dictadura.

\footnotetext{
${ }^{5}$ Ibíd., 44.

${ }^{6}$ Ibíd., 45.
} 
Frente a este tipo de iniciativas, señalaban que las masas y el movimiento popular debían expulsar de sus prácticas y concepciones aquellas ideas y apuestas "pequeño burguesas" de las ayudas o "impulsos externos" para que el pueblo pueda ponerse en marcha y desarrollar sus luchas. Por ello, planteaban que "el verdadero movimiento de masas, capaz de generar una situación revolucionaria es el que se construye a partir de los problemas concretos que enfrenta el pueblo".7 Por esto, el PCCh criticó y rechazó cualquier intento por desarrollar acciones armadas y aisladas de las masas, llamando a realizar principalmente actividades tendientes a la ocupación, mantenimiento y recuperación de espacios y dinámicas políticas democráticas y que por medio de esta fuerza, permitieran el aislamiento político de la dictadura y la anulación o freno de la violencia reaccionaria (represiva) de la Junta Militar. A partir de estas consideraciones, orientó sus esfuerzos por construir una amplia alianza política con la Democracia Cristiana, rechazando de plano, cualquier intento de articulación política con el MIR.

Desde 1974, el PCCh se lanzó con decisión a la creación del Frente Antifascista, señalando la necesidad de aprovechar los supuestos resquebrajamientos que se presentaban al interior de las Fuerzas Armadas producto de las tensiones de algunos generales con Pinochet. De igual modo, otorgaba un gran significado político e impacto entre la militancia democratacristiana, la emergencia de críticas en su interior y el alejamiento de importantes dirigentes demócratas cristianos que fueron parte del entramado golpista respecto de los militares fascistas (ÁLVAREZ, 2003; ROJAS, 2011; BRAVO, 2010). De esta manera, y partiendo de la lectura del amplio margen de rechazo y aislamiento político nacional e internacional en el cual se encontraba la Junta Militar, el PCCh presentaba su propuesta de creación del Frente Antifascista, cuya finalidad era

[...] la derrota de la dictadura, la destrucción del Estado totalitario y policial [...] la construcción de un nuevo estado democrático, nacional, pluralista y popular que desarrolle todas las conquistas que nuestro país y su pueblo han alcanzado, que liquide el poder del imperialismo y de la gran burguesía monopólica y agraria y resguarde los intereses de las grandes mayorías nacionales, construyendo una nueva economía que garantice el desarrollo independiente del país. ${ }^{8}$

\footnotetext{
${ }^{7}$ Boletín del Exterior. Partido Comunista de Chile, 1, enero de 1974, 9.

${ }^{8}$ Boletín del Exterior. Partido Comunista de Chile, 4, mayo-junio 1974, 8.
} 
Agregaban además que la lucha del Frente Antifascista, por sus características y amplitud, generaría el gobierno más democrático que Chile haya tenido y que la lucha por una nueva democracia era el único camino que conduciría "al proletariado y sus aliados a constituir una sociedad superior más justa, la sociedad socialista, sobre la base de un proceso que cuente con el apoyo de la mayoría inmensa del país". 9

En función de lo anterior, es posible sostener que durante la década de 1970, independientemente de que los comunistas agregaran o precisaran algunas temáticas respecto de la derrota de la Unidad Popular (en la cual incluso asumían un nivel importante de responsabilidad), en lo general, estas nuevas reflexiones no implicaron cambios sustanciales en su política de Frente Antifascista y en la centralidad asignada a la Democracia Cristiana en el proceso político de unidad para enfrentar a la dictadura. Lo fundamental para el PCCh era evitar el aislamiento de la clase obrera y acercar a los sectores medios, así como a los sectores democráticos y antifascistas de las FF. AA. y el centro político, principalmente el PDC, hacia el proyecto de transformación social llevado adelante por la izquierda. En la misma línea, ratificaban las diferencias tácticas con el MIR y su crítica al actuar aislado de las masas, al aventurerismo y al terrorismo. Éstas se mantuvieron con fuerza por lo menos hasta el Pleno de agosto de 1977 y en menor medida e intensidad hacia el final de la política del Frente Antifascista, en 1980.

En relación a la trayectoria y características del Frente Antifascista, el grueso de los investigadores que estudian el comunismo chileno en dictadura sostienen que ratificó y dio continuidad a su apuesta histórica de carácter gradualista e institucional respecto del proceso de construcción socialista (frentepopulista), así como también a los elementos centrales de su política de alianzas (amplias) en miras a las transformaciones sociales y en colaboración con la llamada burguesía nacional (MOULIAN Y TORRES, 2010; VARAS, 2010; RIQUELME, 2009; BRAVO, 2010; BASCUÑÁN, 1990; ÁLVAREZ, 2011; ROJAS, 2011; VENEGAS, 2009). En esta línea de análisis, Hernán Venegas (2008, 279) sostiene que incluso en los peores momentos vividos por el PCCh en dictadura, producto de la represión sistemática de la cual era objeto por parte de los cuerpos represivos, éste "volvió su mirada hacia lo

\footnotetext{
${ }^{9}$ Ibíd., 8.
} 
que había sido su propia historia y sostuvo con mucha nitidez desde un comienzo, una postura que mantuvo consonancia con sus propuestas más clásicas”.

Como señalamos al comienzo, nos interesa identificar y comprender las lecturas y concepciones que dieron sustento a la política del PCCh en los primeros años de dictadura y la relación de ésta con la trayectoria y desarrollo de su política militar. Al respecto, creemos que no es posible comprender este proceso sin considerar el contexto histórico particular en el cual se desarrolla la reflexión política y la vida militante, marcada entre otras cosas por la condición política tripartita de derrota-clandestinidad-represión, el exilio masivo de la militancia y sus cuadros de dirección y por último, la tensión y necesidad a la vez de resolver el binomio búsqueda e identificación de las causas de la derrota de la Unidad Popular y la formulación y materialización de una política certera para terminar lo antes posible con la dictadura. Estos elementos de contexto son, a nuestro parecer, los que marcan la tónica del proceso de politización y repolitización de la militancia comunista durante los 1970.

En relación a las dinámicas políticas descritas anteriormente, Rolando Álvarez (2011) señala que la experiencia vivida por el PCCh en el periodo 1973-1980 es de continuidad y cambio a la vez. Por una parte, hay persistencia en el trabajo y la centralidad de la "lucha de masas" y una continuidad clara de su vocación aliancista y moderada; por otro lado, cambio a partir de la experiencia nacida producto de la derrota (prisión, tortura, delación y muerte de sus militantes) y el miedo como cotidianidad en miras a terminar con la dictadura. En otro sentido, señala que este proceso permitió la reconfiguración de la cultura política comunista y, por tanto, la línea del Frente Antifascista se inscribe y sería parte de este mismo proceso de continuidad y cambio. Continuidad, al considerar como éxitos parciales o aciertos de la apuesta, algunos logros obtenidos en el marco de la lucha de masas y el dialogo con la Democracia Cristiana, aspectos que según el autor habrían terminado reforzando la lógica y tradición aliancista. Cambio, en relación a la sensación de fracaso al no poder concretar la unidad política con la Democracia Cristina, lo que habría generado en la militancia comunista la necesidad de repensar y encontrar, en el contexto de la institucionalización y alargue de la dictadura, nuevas formas de lucha. Y, compartiendo con esto, queremos justamente identificar y 


\section{La política militar del PCCh durante la política del Frente Antifascista}

En relación a la política militar del PCCh, creemos necesario señalar al menos tres consideraciones. La primera debe ser caracterizada y analizada a la luz y en directa relación con su política general, en este caso la política del Frente Antifascista. La segunda, la política militar, también se encuentra sometida o marcada por las dinámicas de continuidad y cambio, sobre todo considerando el contexto en el cual se formula y materializa la política (derrota-represión-clandestinidad), los escenarios y las experiencias militantes vividas en las diversas estructuras y espacios políticos partidarios (por ejemplo, la militancia en el exilio y los espacios de reflexión y debate que alimentaron dicha formulación y desarrollo, Cuba y la República Democrática Alemana, entre otros). La tercera, la política militar del PCCh durante este periodo está estrechamente vinculada a los balances políticos que desarrolló este partido en relación a la trayectoria de la vía chilena al socialismo y particularmente respecto de la derrota de Allende.

En realidad, estimamos que dichas reflexiones y balances se convirtieron en una importante fuente general de alimentación de la política militar del PCCh para el periodo 1973-1977. Del mismo modo, nos entregan importantes elementos que permiten comprender los sentidos y el carácter de las apuestas que desarrolló dicho Partido en relación al problema militar durante este proceso. Del mismo modo, estimamos posible dar cuenta de la política militar del PCCh para este particular periodo, a partir de dos grandes aspectos. Uno de ellos, su visión (balance) sobre las FF. AA. y el papel de éstas en el Golpe de Estado; el otro, dice relación con el problema de las formas de lucha. En conjunto, esto es fundamental para comprender la mayoría de las decisiones políticas tomadas por este partido en relación al problema militar, así como también respecto a su política hacia las FF. AA. en el contexto de lucha contra la dictadura.

En relación a la visión del PCCh sobre las FF. AA. chilenas, éste fijó tempranamente (a meses de instalada la Junta) sus preocupaciones y parámetros por los cuales debía ubicarse su política frente a ellas. Por ejemplo, estableció que el pueblo chileno tenía 
[... ] derecho a plantearse también como objetivo la creación de fuerzas armadas y policiales de nuevo tipo, o, al menos, a eliminar de los institutos militares, carabineros e investigaciones, a los elementos fascistas a fin de asegurarle a Chile que nunca más se repetirá lo que acaba de ocurrir. ${ }^{10}$

A partir del análisis de la gran mayoría de los documentos y declaraciones del PCCh en los cuales se aborda el tema de las Fuerzas Armadas, es posible señalar que el grueso de sus formulaciones políticas tendió a identificar y separar a los sectores golpistas por un lado y la institución (FF. AA.) por otro. Esto implicó caracterizar y comprender a los sectores golpistas de las Fuerzas Armadas como facciones o incluso como sectores traidores o ajenos a ellas, cuando establecieron, por ejemplo, que dichos sectores fascistas llevaron a las FF. AA. chilenas a romper con sus tradiciones democráticas, debido principalmente a la adscripción de éstos a la Doctrina de Seguridad Nacional y los objetivos e intereses del imperialismo.

La idea de arrastre del conjunto de las instituciones castrenses por los sectores golpistas instala la concepción de unas FF. AA. escindidas, fragmentadas, en disputa y sin cuerpo. Bajo esta óptica, serían los sectores golpistas y no el conjunto de las FF. AA. los que llevaron adelante el Golpe de Estado y la cruenta represión hacia el movimiento popular y la izquierda: "los generales y oficiales que aceptaron las presiones externas e internas para arrastrar a sus instituciones a participar en la conspiración contra Chile y su pueblo" habrían pisoteado "el prestigio y la solvencia de las FF. AA. ante el pueblo y el mundo y terminarán destruyéndolas si perseveran en su orientación”."

Lo interesante de estas lecturas es que sirven como base para la formulación y justificación de su política hacia las FF. AA., por tanto, para su política militar, afirmando, por ejemplo, que como Partido, tanto bajo el gobierno de Allende como en dictadura, nunca han concebido "la lucha social como un combate entre civiles y uniformados", ya que existían sectores al interior de las Fuerzas Armadas que vestían "el uniforme pensando en sus deberes para con la patria y han sido conducidos a participar en el terror

\footnotetext{
${ }^{10}$ La voz de orden es la unidad, op. cit., 28.

${ }^{11}$ Unir millones para poner término a la pesadilla (declaración formulada en Santiago, el 20 de diciembre de 1973), In: Desde Chile..., op. cit., 43.
} 
desatado contra el pueblo pese a sus sentimientos democráticos". Por esto, disponía que uno de los esfuerzos principales del movimiento popular debía estar dirigido a

[...] hacer pesar ante los soldados y oficiales los sentimientos democráticos y progresistas de la mayoría y evitar, en aras del interés de la patria, que las FF. AA. se transformen definitivamente en cancerberos de los intereses del imperialismo y la oligarquía. ${ }^{12}$

En la misma línea, establecían que las Fuerzas Armadas contaban todavía en su interior con una alternativa "honrosa, honesta, patriótica" contraria a "la del custodio del privilegio económico y verdugo de su pueblo”. Según el PCCh, esta línea había sido demostrada por el General Schneider y el General Prats, y por "muchos otros, que fueron sacrificados por negarse a abjurar de sus traiciones a violar sus deberes", y que el desplazamiento de los sectores constitucionalistas al interior de las FF. AA. y la instalación de la traición entre sus miembros, implicó el rompimiento de las tradiciones democráticas y el abandono del profesionalismo a costa de ponerse al servicio de los intereses de una minoría. Partiendo de ello, establecían que las Fuerzas Armadas chilenas debían "volver a la observación de las tradiciones de constitucionalismo y profesionalismo que los honraron y distinguieron en el mundo, mientras la practicaron y del que jamás debieron apartarse". ${ }^{13}$

Como hemos visto hasta ahora, la creación de nuevas FF. AA. y la eliminación de los elementos fascistas ubicados al interior de los cuerpos militares, se instalaron como preocupación principal y se convirtieron igualmente en importantes objetivos políticos militares dentro de la apuesta general del PCCh para este periodo y, sobre todo, para un supuesto escenario de término de la dictadura e inicio del proceso de recuperación democrática. A partir de estas concepciones, podemos sostener que la apuesta política fundamental a partir de entonces, el objetivo político más específico y estratégico a la vez era evitar nuevamente, en un hipotético escenario, la reedición del proceso de agrupamiento político y militar llevado adelante por los sectores reaccionarios y fascistas al interior de las FF. AA. en función del rechazo al proceso de democratización de la

\footnotetext{
12 Ibíd., 44.

${ }^{13}$ Ibíd., 131-132.
} 
sociedad chilena, en miras a las transformaciones socialistas. En definitiva, evitar la emergencia de tendencias golpistas y fascistas, sosteniendo que "lo que Chile requiere y exige son FF. AA. que nunca más, bajo ninguna circunstancia, se contrapongan a los intereses del pueblo y se conviertan, como instituciones, en cancerberos de los intereses de la oligarquía y el imperialismo". ${ }^{14}$ Estas apuestas, fijadas muy tempranamente por la dirección del PCCh, se convertirán en los pilares estructurantes y en los elementos ordenadores de su política hacia las FF. AA., por lo menos hasta fines de los 1970.

En esta misma línea de análisis, plantean que un problema central a resolver por el Frente Antifascista en las tareas de reconstrucción democrática, es el "asegurar una profunda transformación en las FF. AA. y Carabineros", de lo cual concluyen, "la instauración y permanencia del Estado democrático al que aspiramos no estaría garantizado sin resolver ese problema”. A su juicio, la articulación en torno a estos objetivos, las tareas encaminadas a su materialización y el cumplimiento de ellos, no solo recaían o eran responsabilidad exclusiva de la izquierda chilena y el movimiento popular, "sino también de los soldados y oficiales profesionales y democráticos". ${ }^{5}$ Señalan, además, que es en las propias filas de los uniformados donde debía tomarse la "decisión de contener a los jefes fascistas que ordenan y siguen ordenando que las Fuerzas Armadas manchen sus manos con sangre de hombres y mujeres del pueblo". ${ }^{16}$ Por ello, concluyen que todo sector con espíritu democrático y patriótico al interior de las Fuerzas Armadas chilenas "tiene un lugar en el Frente Antifascista", precisando al respecto que estos mismos sectores debían tomar "las medidas correspondientes para contener primero el crimen y la tortura y para juzgar y sancionar enseguida a los que deben responder por todos los crímenes cometidos contra el pueblo".

Como podemos observar, el PCCh no solamente mantenía en su análisis (y con ello en su política militar) el supuesto político respecto a la existencia y permanencia al interior de las Fuerzas Armadas chilenas de un segmento de militares profesionales y democráticos, los cuales, además, en la lectura del PCCh, podían y debían jugar un rol

\footnotetext{
${ }^{14}$ Los acontecimientos en Chile: visión de los comunistas (enviado desde Santiago, en junio de 1974, a Revista Internacional, que lo publicó en junio y agosto de 1974), In: Desde Chile..., op. cit., 104.

${ }^{15}$ Ibíd., $103-104$.

${ }^{16}$ Al Partido y al pueblo de Chile. Santiago, 20 de diciembre de 1974, 148.
} 
protagónico en el término de la dictadura, conservando la concepción y la apuesta política que otorgaba un papel central a este sector de las Fuerzas Armadas en el proceso político de recuperación democrática, así como en el resguardo y garantía del proceso de transformaciones sociales estructurales revolucionarias venideras.

Estos elementos, concepciones y apuestas, a nuestro parecer, son de continuidad, casi irrestricta respecto de su política militar, son parte de la misma lógica con la cual se pensó y articuló la política militar del PCCh durante la Unidad Popular. A nuestro entender, el peso y la centralidad en la política militar del PCCh durante el Frente Antifascista recaía en gran medida en las propias FF. AA. y en las dinámicas de politización que debían desarrollarse en su interior. Tanto así, que su protagonismo determinaba o incidía notablemente en otros aspectos políticos a definir y desarrollar en el marco de la confrontación con la dictadura, por ejemplo, respecto a las formas de lucha: "el desarrollo político que sigan las FF. AA. y Carabineros es un factor que determinará muy decisivamente tanto el carácter como la forma que asuma la resistencia antifascista". ${ }^{17}$ De igual forma, sostenemos que a partir de los balances realizados sobre la derrota de Allende, los cuales fueron incorporando con mayor frecuencia elementos de análisis vinculados al papel de las FF. AA., así como también desde las apuestas levantadas por el PCCh para terminar con la dictadura y enfrentar el proceso de recuperación democrática, emergieron una cantidad importante de problemáticas y nuevas discusiones en relación a los temas militares que, en algunos casos, se resolvieron a través de procesos políticos formales y a nivel de dirección política, como las desarrolladas en torno a la tesis del vacío histórico en el marco del Pleno del Comité Central, en 1977.

En otros casos, los problemas abiertos por las discusiones previas en este contexto se enfrentaron de manera concreta y parcelada, incluso sin grandes definiciones o precisiones por parte de la dirigencia comunista, ya sea en términos de perspectivas o impacto político. Por ejemplo, la creación en la República Democrática Alemana de equipos de trabajo dedicados a investigar la trayectoria de las FF. AA. chilenas, el problema militar y las causas de la derrota de la Unidad Popular, o igualmente la decisión de formar militares profesionales de alto rango en las Fuerzas Armadas Revolucionarias

\footnotetext{
${ }^{17}$ Ibíd., 148.
} 
de Cuba, a partir de 1975 (ÁlVAREZ, 2006; PÉREZ, 2012; PÉREZ, 2013). Por otro lado, emergieron una cantidad significativa de nuevas temáticas y problemáticas a partir de la materialización y desarrollo de las iniciativas políticas levantadas por la dirección del PCCh en función de enfrentar y llenar algunos problemas o vacíos en su política militar.

En el caso de los equipos en la RDA y los militares profesionales en Cuba, en el corto plazo no solo permitieron el surgimiento de nuevas cuestiones políticas que debían tratarse y definirse, sino, además, terminaron aportando en el mediano plazo a los procesos de reconfiguración política del PCCh y contribuyendo, entre otras cosas, a la necesidad de repensar algunos preceptos básicos de la trayectoria comunista, lo que terminó aportando al surgimiento de la Política de Rebelión Popular de Masas, a partir de 1980, y a la ampliación y desarrollo de la política militar del PCCh en ámbitos hasta este momento desconocidos. Por ejemplo, el "Trabajo Militar de Masas", que significaba la incorporación de lo militar en la totalidad de las estructuras partidarias, y, por otro lado, a la creación por primera vez en su historia partidaria, de una Fuerza Militar Propia, el Frente Patriótico Manuel Rodríguez.

\section{Balance y autocrítica comunista en relación a la Política Militar en tiempos de la Unidad Popular}

Respecto a la idea de continuidad en la política militar del PCCh durante el Frente Antifascista, la podemos corroborar a partir del estudio de los principales análisis y balances realizados por la propia dirigencia y militancia comunista en relación al carácter y la concepción de su política militar durante la Unidad Popular. La gran mayoría de estas reflexiones releva la casi exclusividad que tuvo, por parte del PCCh, el trabajo hacia las Fuerzas Armadas en el desarrollo de su política militar durante el gobierno de Allende. Al respecto, Luis Corvalán (Secretario General del PCCh entre 1958 y 1990) señala en sus memorias que concentraron gran parte de los esfuerzos entorno a las Fuerzas Armadas, particularmente en los altos mandos constitucionalistas. A pesar de ello, precisa, él mismo le habría planteado al presidente Allende que el PCCh no consideraba pertinente "formar partido en el seno de las instituciones militares" (CORVALÁN LEPE, 1997, p.179). 
En relación a estas problemáticas y haciendo referencias al Pleno de agosto de 1977, señala que lo más importante desde el punto de vista político son los elementos concluyentes del informe en relación al problema militar. Según ello, en el Pleno se estableció "como un vacío histórico de nuestro Partido el hecho de no tener un claro conocimiento del mundo militar y carecer de una política militar". De alguna manera, profundiza, se estableció la creencia de un Chile particular, distinto, entre otras cosas porque las "Fuerzas Armadas se distinguían por su profesionalismo y su prescindencia en la vida política". No obstante, reconoce que tiempo antes del Golpe de Estado, venían observando "que era una concepción falsa", y que habría sido "el golpe fascista que derribó al gobierno del Presidente Salvador Allende lo que nos hizo ver la realidad tal cual es, demostrando hasta la saciedad esa falacia" (CORVALÁN LEPE, 1997, p. 254-255).

La afirmación anterior es de enorme importancia, ya que conceptualiza y sintetiza una evaluación política sobre la experiencia chilena y las causas de la derrota, particularmente a partir de uno de los tópicos menos abordados por este partido, el problema militar. De igual forma, se puede desprender de dicha evaluación-conclusión que la centralidad de la política militar del PCCh reposaba principalmente sobre una construcción realizada por este partido sobre la historia de Chile y sus instituciones y más particularmente sobre la visión que edificó respecto de las FF. AA. chilenas (FURCI, 2008). En base a estas concepciones se levantó su política militar y estableció en ella la centralidad del trabajo hacía las Fuerzas Armadas como lo fundamental.

Por su parte y siguiendo la misma línea de análisis, Guillermo Teillier ${ }^{18}$ señala que en el Pleno de 1977 se concluyó también que no supieron defender las conquistas y las transformaciones desarrolladas durante la Unidad Popular, lo que hizo de los aspectos militares de la política una de las mayores debilidades en la trayectoria del partido. Señala también que no es correcto concluir la no existencia de una concepción del trabajo militar, que estaría sustentada en "el trabajo de relaciones con las Fuerzas Armadas institucionales". Señala al respecto que antes del triunfo de Allende y durante su

\footnotetext{
${ }^{18}$ Guillermo Teillier, Secretario General del PCCh entre 2002 y 2005, y de 2005 a la actualidad su Presidente; integrante del Equipo de Dirección Interior en el período de la clandestinidad y encargado de la Comisión Militar durante el despliegue de la política de rebelión popular, entre 1982 y 1987 (HERREROS, 2003, 206).
} 
gobierno estimaban contar con un número importante de altos oficiales, suboficiales y tropas leales al gobierno y con ideario constitucionalista, lo que implicaba que "de alguna u otra manera estaban por respetar la voluntad popular". Estima en relación a la política militar del PCCh y en torno a la derrota de la Unidad Popular que lo principal fue no haber preparado "políticamente al pueblo para defender el Gobierno. Eso era lo más importante". ${ }^{19}$ Por el contrario, agrega que primó la política de no producir situaciones que justificaran respuestas por parte de los sectores reaccionarios y golpistas.

Más, considera que no tomaron en cuenta "que era una especie de fatalidad, que igual iba a venir, porque ya habían demasiados indicios [...] no podíamos hacernos los lesos, y sin embargo sacamos la consigna No a la Guerra Civil”. Frente a esto, especifica que no querían una guerra civil, no obstante "quizás la consigna desde el comienzo debió haber sido Hay que Defender al Gobierno Popular y las Conquistas de los Trabajadores. Debimos haber llamado y habernos preparado desde un comienzo para eso". Por último, autocríticamente señala que en base a la importancia asignada por el partido al trabajo con las FF. AA., de las cuales se estimaba existir apoyo de importantes segmentos constitucionalistas, no solamente para hacer respetar la constitución, sino además la voluntad popular, correspondía haber profundizado y trabajado mucho más con estos segmentos, así como también debieron "haber tratado de cambiar el carácter de las FF. AA., desde el punto de vista doctrinario, de los cuadros de los mandos, etc.". ${ }^{20}$

En relación a estas mismas problemáticas, Francisco Herreros señala que la concepción militar del PCCh se basaba en "la confianza, profesionalismo y subordinación constitucional de las Fuerzas Armadas chilenas" y tenía como objetivo "la construcción de una correlación de fuerzas políticas y sociales lo suficientemente amplia y sólida que las disuadiera de apartarse de ese cause" (HERREROS, 2003, 185). Por otro lado, al analizar la política militar del PCCh, así como la trayectoria política de este Partido hasta la Unidad Popular, Luis Rojas señala que durante “casi toda su existencia, en el partido predominó el convencimiento de que las Fuerzas Armadas se subordinaban a la autoridad civil y obedecían la Constitución de la República" (ROJAS, 2011, p.170).

\footnotetext{
${ }^{19}$ Entrevista citada en HERREROS (2003, 206-207).

${ }^{20}$ Ibíd. 207-208.
} 
Otros elementos de análisis y caracterización de la política militar del PCCh durante la Unidad Popular la entrega el testimonio de Carlos Toro, Subdirector de Investigaciones (policía civil) durante el Gobierno de Allende y miembro de la Comisión Militar del PCCh en el contexto del Golpe de Estado. Según ello, el PCCh sí tenía una política militar durante este periodo y a través de su Comisión Militar desarrolló planes operativos en función de la defensa del Gobierno, que fueron pensados con la consideración de la participación de importantes fuerzas políticas y sociales. Según Toro (2007, p.56), el "plan partía de la base que los principales baluartes para la defensa del Gobierno Popular eran los trabajadores y campesinos organizados, las masas estudiantiles y juveniles, en otras palabras el pueblo". No obstante, la parte central del plan recaía material y militarmente en el segmento constitucionalista de las Fuerzas Armadas, de Carabineros e Investigaciones. A juicio de Toro, desde el punto de vista político, lo fundamental "era la defensa del Gobierno, de la Constitución, del imperio de la ley y de la democracia. La necesidad de aplastar cualquier intento golpista". Para ello, se consideraba en el plan o se "partía de la base que los golpistas no contarían con la dirección del Ejército, no contarían con el Comandante en jefe del Ejército, General Carlos Prats" (TORO, 2007, p.30).

Precisa, además, que militarmente el plan de defensa del Gobierno se construyó teniendo en cuenta ciertas premisas políticas fundamentales para el PCCh. Una de ellas, quizás la principal, dice relación con la disposición de las fuerzas al interior del Ejército: se pensaba, señala Toro, que los golpistas no contaban con la totalidad de las fuerzas militares en esta rama de las FF. AA., y que tanto el General Carlos Prats, Comandante en Jefe, como la mayoría del cuerpo de generales asumía la llamada Doctrina Schneider, "que implicaba prescindencia política de los uniformados, acatamiento y defensa del Gobierno Constitucional, sujeción a las directrices del Presidente de la República y el derecho de este a cumplir el programa ofrecido al pueblo" (TORO, 2007, p.57).

Son justamente las debilidades o vacíos de la política militar del PCCh en tiempos de la Unidad Popular, las que comienzan a resolverse en el transcurso de los primeros años de la dictadura. De ahí la importancia de revisar y considerar la autocrítica comunista, ya que permite percibir las dinámicas de continuidad y cambio que marcaron 
este periodo de la historia partidaria, así como también los elementos que tensionaron la política militar del PCCh en los tiempos del Frente Antifascista.

\section{Las formas de lucha y la política militar del PCCh bajo el Frente Antifascista.}

Otra forma de identificar los rasgos más importantes y generales de la política militar del PCCh es mediante el análisis de las apuestas tácticas que levanta y las concepciones políticas que hay detrás de ellas. Éstas, por ejemplo, fijan los contornos y las dinámicas fundamentales por las cuales debían transitar y desarrollarse las formas de lucha asumidas por el PCCh en contra de la dictadura. Al igual que las referencias políticas hacía las FF. AA., las formas de lucha establecidas y desarrolladas por el PCCh nos entregan significativos elementos para identificar y caracterizar la política militar, su visión sobre las FF. AA. y la política de este partido hacia ellas.

En relación a las formas de lucha, ya señalamos que un importante elemento de la tradición política comunista es la centralidad asignada a la lucha de masas en el proceso revolucionario. Al respecto, podríamos plantear una especie de consenso entre los investigadores dedicados al estudio de la izquierda chilena y particularmente del comunismo chileno en relación a esta afirmación, siendo que algunos autores señalan que el PCCh lo hizo tanto en los peores pasajes represivos de su historia partidaria como en los momentos de mayor auge y radicalización política en el marco de la lucha contra la dictadura, sobre todo, en el periodo 1983-1988 (MOULIAN Y TORRES 2010; VENEGAS, 2009; ÁlVAREZ, 2011; BRAVO, 2010). Así, durante la política del Frente Antifascista, la lucha de masas no perdió importancia y se convirtió en punto fundamental de todo el repertorio político más recurrente en sus declaraciones y documentos. Como cierre o consigna final, siempre aparecía la centralidad de la lucha de masas en la gran mayoría de los documentos partidarios. Lo interesante, también, es que como contraparte, aparecía una importante crítica y recurrente rechazo a las formas armadas de lucha propiciadas por el MIR en contra de la dictadura, sobre todo en el periodo 1973-1977.

Por ejemplo, en una declaración pública del 15 de diciembre de 1973, el PCCh sostenía que "el terrorismo y la provocación son ajenos a la línea de combate del pueblo 

aventurerismo, concluyendo que “iLa lucha de masas es el único camino de victoria!”. En función de esto, el PCCh fija de forma clara las dinámicas principales que configurarían las formas de lucha a desarrollar por su militancia. Éstas debían determinarse considerando la necesidad de aglutinar la totalidad de las fuerzas democráticas que se oponían al fascismo. Debían contemplar en cada situación "el nivel de conciencia alcanzado por las masas", así como "la correlación real de fuerzas existentes y la necesidad de que cada acción mejore esa correlación de fuerzas en favor del pueblo". ${ }^{21}$

Una vez claros estos criterios, establecían que el camino "del terror individual o del putsch" debería ser evitado. Según el PCCh, la Junta esperaba que "el pueblo se deslice a ese tipo de acción", ya que les permitía justificar su política represiva. Concluían en base a la experiencia histórica y el escenario que se abría con la instalación de la Junta Militar, que tiempo atrás "el ultrismo y la provocación prestaron considerable ayuda a los enemigos del pueblo. Del mismo modo ahora, la acción aventurera es lo que quiere el fascista Leigh para imponer su juego" ${ }^{22}$. En este contexto, la apuesta del PCCh se centró en desarrollar un amplio movimiento de masas en contra de la Junta Militar a objeto de profundizar su aislamiento, ya que ningún proceso revolucionario podrá triunfar si no cuenta con una amplia fuerza de masas. Por último, reafirman nuevamente la política militar llevada adelante durante la Unidad Popular, al plantear la salida al conflicto en base a la construcción de una amplia mayoría en rechazo a la dictadura (en tiempos de la Unidad Popular era en contra de los sectores golpistas), que permita una correlación favorable de fuerzas capaz de frenar o "amarrar las manos" de aquellos sectores que quisieran desatar la violencia en contra de la mayoría del país.

\footnotetext{
${ }^{21}$ El Partido Comunista denuncia provocación. Santiago, 15 de diciembre de 1973, In: Desde Chile..., op. cit., 37 y 46.

22 Ibíd. Más adelante, en “Los Acontecimientos de Chile: Visión de los Comunistas”, de junio de 1974, plantean la misma idea pero cambiando el concepto ultrismo por terrorismo: "En el pasado, el terrorismo y la provocación prestaron considerable ayuda a los enemigos del pueblo. Ahora, dado el tipo de opresión, el resultado sería peor" (Desde Chile..., op. cit., 105).
} 
Al respecto, estimamos existir una importante continuidad política entre los lineamientos emanados para enfrentar a la Junta Militar y aquellos levantados por el PCCh en el último periodo de la Unidad Popular, sobre todo en las concepciones y apuestas que lanzaron para enfrentar los embates de los sectores reaccionarios y golpistas y que fueran sintetizados en la consigna No a la Guerra Civil. Lo fundamental y decisivo para el PCCh, no solo en relación a los objetivos vinculados a la construcción y materialidad del Frente Antifascista, sino además respecto a la derrota de la dictadura, “es el trabajo de masas". No hay, a juicio del PCCh, "ninguna táctica que pueda reemplazar este trabajo como el asunto clave de la victoria. Ninguna salida, no importa cuál sea su forma, puede prescindir de la acción de masas. Su participación decide la victoria". Planteaban, entonces, evitar la emergencia en el movimiento popular de concepciones y actitudes de expectativa pasiva, de una solución que emanase por fuera del movimiento de masas, y señalaban que la Junta Militar masificaría la idea respecto a la emergencia de supuestos gobiernos paralelos en el exilio y "que grupos armados se prepararían en el exterior para derrocarla", mancillando el movimiento de solidaridad internacional en contra de la dictadura, mostrándolo como algo externo e intervencionista, y arrastrando "a las masas populares a la inactividad, a la tolerancia pasiva de la explotación y el abuso, en espera del 'gran día' o de la 'gran acción' que decida el cambio". ${ }^{23}$

Sin duda, una de las producciones partidarias más importantes en torno a formas de lucha, así como de la política militar llevada adelante por el PCCh durante el Frente Antifascista, es el documento denominado “El ultraizquierdismo, caballo de Troya del imperialismo". A través de este documento, el PCCh lleva adelante una discusión política con el MIR, por una parte, respecto a la problemática abierta en la izquierda chilena en función de la caracterización de la dictadura, por otra, en relación a la táctica política a desarrollar para terminar con ella. Mención especial adquieren en este sentido las discusiones planteadas en torno a la política de alianzas, el trabajo hacia las Fuerzas Armadas y las formas de lucha a desarrollar por la izquierda chilena y el movimiento popular en contra de la dictadura, concretamente el tema de la lucha armada.

\footnotetext{
${ }^{23}$ Al Partido y al pueblo de Chile. Santiago, 20 de diciembre de 1974, In: Desde Chile..., op. cit., 149.
} 
En relación al tema militar, establecen que como partido de la clase obrera asumen la necesidad de enfrentar el problema militar, entendiéndolo como "la correlación de fuerzas en el nivel militar, que es la correlación inmediatamente decisiva en la definición de la lucha por el poder". Que lo central en torno a esta problemática es la "creación de esa correlación de fuerzas militares favorable al proceso revolucionario, capaz de prevenir y aplastar los intentos de la reacción por perpetrar sus privilegios recurriendo a las armas". En la misma línea, precisan que no puede existir una correlación favorable de fuerzas a nivel militar capaz de garantizar la victoria del proceso revolucionario, "si no se construye una correlación de fuerzas políticas favorable", es decir, "si no se consigue aunar en torno a las fuerzas revolucionarias fuerzas sociales mayoritarias frente a las que logren agrupar los enemigos del pueblo", para concluir que fue justamente "la consolidación de esa condición previa, necesaria, lo que no conseguimos en el período del Gobierno Popular y lo que determinó, básicamente nuestra derrota”. ${ }^{24}$

Respecto de la política militar del PCCh durante la Unidad Popular, señalan que ésta se orientó principalmente a reforzar "las posiciones constitucionalistas en el seno de las FF. AA.", visiones o concepciones políticas "que significaban respeto al Gobierno Popular y que enfrentaban los esfuerzos de los fascistas por convertir a las FF. AA. en restauradores del poder de la oligarquía y el imperialismo". Se esperaba, a partir de estas posiciones, que las FF. AA. se vincularían al proceso de desarrollo económico y social llevado adelante por la Unidad Popular, ya que esto beneficiaba la mayoría de la nación. En el transcurso de este proceso, señala el PCCh, tendría que haberse producido "una identificación creciente de los integrantes de las FF. AA. con las necesidades de progreso del país, y con ello con el proceso revolucionario". Y, según el PCCh, el fracaso de esta política se debió principalmente al cambio en la correlación de fuerzas políticas en desmedro del movimiento y del Gobierno Popular, al hecho de que las orientaciones políticas en relación a las FF. AA. no se materializaron orgánicamente por el conjunto de las fuerzas políticas que constituían la Unidad Popular y a la sobredimensión de las

\footnotetext{
${ }^{24}$ El Ultraizquierdismo, Caballo de Troya del Imperialismo. Santiago, septiembre de 1975, In: Desde Chile, op. cit., 225-226.
} 
capacidades de los sectores constitucionalistas en los cuerpos militares, así como también “el peso de los sentimientos democráticos al interior de los institutos armados". 25

En relación al trabajo hacía las Fuerzas Armadas, podemos identificar en primer lugar una clara correspondencia entre su apuesta política hacía los cuerpos militares y su política general, el Frente Antifascista. Para el PCCh, la definición e inscripción del trabajo hacía las Fuerzas Armadas se debía dar en el marco de la contradicción política principal establecida por este partido para este periodo, es decir, entre fascismo y democracia. En función de esto, la tarea que fijó el PCCh en este contexto era "hacer pesar en el seno de esas instituciones los sentimientos e ideas de la mayoría del país”. En relación a esta línea de trabajo, precisan, había que considerar "de preferencia a soldados, clases y suboficiales", ya que debido a su condición de clase se encontraban vinculados más directamente con los problemas de la mayoría del pueblo, permitiéndoles comprender más fácil y rápidamente la urgencia de terminar con la dictadura. No obstante, señalan que "con diferencia de grado, esto pesa también en la oficialidad, vinculada mayoritariamente a las capas medias expoliadas agudamente por el fascismo" ${ }^{26}$.

Teniendo como base las concepciones y argumentos anteriores, plantean que el Frente Antifascista debía tener entre sus objetivos la necesidad de construir unas FF. AA. leales al pueblo, que respeten realmente "el poder político que el pueblo resuelva darse libremente". En estas instituciones militares, precisan, no tendrán cabida los sectores fascistas, vinculados a la tortura y a la corrupción. Respecto al involucramiento de los militares en el proceso y las dinámicas de lucha contra la dictadura, señalan como decisivo en el despertar del sentimiento antifascista de la mayoría de los miembros de las FF. AA., el ascenso y desarrollo de la lucha de masas, particularmente la impulsada por la clase obrera y el pueblo: a partir de la movilización de "las grandes masas se abrirán paso con fuerza los sentimientos antifascistas en el seno de las FF. AA. y la unidad del pueblo y los integrantes de las FF. AA. cristalizarán en el curso mismo de esos combates de clase". ${ }^{27}$

\footnotetext{
25 Ibíd., 226.

${ }^{26}$ Ibíd., 227-228.

${ }^{27}$ Ibíd., 228.
} 
En relación a las formas de lucha, plantean una importante relación política entre la centralidad de la lucha de masas y la política militar, estableciendo una dura crítica al actuar "aventurero" y "terrorista" del MIR: "el ultraizquierdismo se mantiene aferrado al terrorismo como elemento decisivo de todo su proyecto político", criticando las acciones armadas contra la dictadura tales como la propaganda armada, el hostigamiento de los aparatos represivos o el castigo de torturadores, asesinos o agentes de la dictadura. Respecto de estas formas de lucha, las definen como de carácter o parte de "un plan terrorista, aunque en las acciones no murieran sólo inocentes", porque "cada una de estas 'tareas' no podrán ser sino acciones de individuos o pequeños grupos separados de las masas y nunca de las masas mismas en las condiciones actuales". Para el PCCh, solamente "a través de la lucha de masas se creará una situación revolucionaria y con ello las condiciones básicas para conseguir una correlación política y una correlación militar favorable a las fuerzas populares". Por esto, plantear la construcción de un "poder militar proletario y popular", como postulaba el MIR, a partir del accionar terrorista, es un delirio, no solo porque significa construir una fuerza militar superior a las de las FF. AA. chilenas, sino fundamentalmente porque se conciben "al margen de la lucha real de clases". ${ }^{28}$

Considerando lo expuesto, estimamos que el PCCh reconoció las debilidades e insuficiencias de su política militar durante el Gobierno de la Unidad Popular (a propósitos de los análisis respecto de la derrota de Allende), así como dio continuidad a ella durante la política del Frente Antifascista. Estos aspectos los podemos identificar en numerosos documentos y declaraciones partidarias elaboradas tanto por la dirigencia comunista ubicada en Chile como en el exilio. Ejemplo de lo último son los planteamientos de Américo Zorrilla, miembro de la Comisión Política del PCCh, quien sostenía ser obligatorio “preparar a la clase obrera y a las masas para enfrentar la contrarrevolución en todos los terrenos, comprendido el militar. La tarea de defender la revolución exige dominar y estar en condiciones de aplicar todas las formas de lucha". ${ }^{29}$

\footnotetext{
${ }^{28}$ Ibíd., 231-232.

${ }^{29}$ Acerca de Lenin y la defensa de la revolución, In: Don Américo, op. cit. (1993, 141).
} 
Al respecto, creemos que durante el periodo 1973-1977 el PCCh ya había enfrentado políticamente algunos aspectos y problemas centrales de su política militar y que fueron catalogados posteriormente en el Pleno de 1977 como "vacío histórico". En este sentido, el "vacío" ya se venía llenando desde que se reconocieron las limitaciones de su política, se formaron en 1974 los primeros equipos para el tratamiento de estas problemáticas y se dio inicio al proceso de formación de militares profesionales en Cuba a partir de abril de 1975. Estas apuestas son sumamente coherentes con la política general del PCCh y tienen directa relación con los balances realizados por la dirigencia comunista respecto de la experiencia chilena, las necesidades a resolver para enfrentar a la dictadura y para enfrentar los desafíos en un hipotético escenario de recuperación democrática. Lo importante a nuestro juicio, fue el recorrido o la trayectoria de estas iniciativas, su desarrollo político particular en el marco general de lucha contra la dictadura, de las discusiones partidarias internas y de la experiencia concreta en torno a la especificidad de sus tareas. En este sentido, cabría plantear que las iniciativas políticas llevadas adelante por el PCCh para resolver gran parte de sus debilidades en cuanto a su política militar, también produjeron una cantidad importante de nuevos vacíos. En definitiva, los vacíos que debían llenar en relación a la política militar, después del Pleno de 1977, no fueron pensados en función de cómo defender las conquistas de la clase trabajadora y el pueblo en un nuevo hipotético gobierno popular, sino en miras a la derrota de la dictadura.

Este último aspecto-objetivo, se convertirá en uno de los elementos ordenadores de la política militar del PCCh desde fines de la década de los 1970, como queda reflejado en el Pleno del Comité Central del PCCh de 1979, donde aparece por primera vez la preocupación por el desarrollo de su Fuerza Militar Propia, todo esto ante el inminente alargue e institucionalización de la dictadura. ${ }^{30}$ Será en este contexto histórico y a partir del surgimiento de la Política de Rebelión Popular de Masas, en septiembre de 1980, que patrocinaba todas las formas de lucha para terminar con Pinochet, incluida la violencia, donde nacerán y tomarán protagonismo - junto al tradicional trabajo hacia las Fuerzas Armadas - el Trabajo Militar de Masas y la Fuerza Militar Propia (Frente Patriótico Manuel Rodríguez), los nuevos componentes de la política militar del PCCh durante los 1980.

\footnotetext{
${ }^{30}$ Informe al Pleno del Comité Central del Partido Comunista de Chile (1979).
} 


\section{Referencias}

\section{Documentaciones}

Boletín del Exterior. Partido Comunista de Chile.

Desde Chile hablan los comunistas! Santiago: Ediciones Colo-Colo, 1976.

Don Américo. Un chileno Comunista. Homenaje póstumo. Santiago: s/e, 1992.

Informe al Pleno del Comité Central del Partido Comunista de Chile. 1979. En: Hacia el XV Congreso del Partido Comunista de Chile. Documentos para el enriquecimiento del debate. Santiago, 1989.

\section{Libros, periódicos y tesis}

ÁLVAREZ, Rolando. Desde las sombras. Una historia de la clandestinidad comunista (19731980). Santiago: LOM, 2003.

ÁLVAREZ, Rolando. ¿La noche del exilio? Los orígenes de la rebelión popular en el Partido Comunista de Chile, In: VALDIVIA, Verónica; ÁLVAREZ, Rolando y PINTO, Julio. Su revolución contra nuestra revolución. Izquierdas y derechas en el Chile de Pinochet (19731981). Santiago: LOM, 2006, 101-152.

ÁLVAREZ, Rolando. Arriba los pobres el mundo. Cultura e identidad política del Partido Comunista de Chile entre democracia y dictadura. 1965-1990. Santiago: LOM, 2011.

BASCUÑÁN, Carlos. La izquierda sin Allende. Santiago: Editorial Planeta, 1990.

BRAVO, Viviana. ¡Con la razón y la fuerza, venceremos! La rebelión popular y la subjetividad comunista en los '80. Santiago: Ariadna Ediciones, 2010.

CAMPERO, Guillermo. Los gremios empresariales en el periodo 1970-1983: Comportamiento sociopolítico y orientaciones ideológicas. Santiago: ILET, 1984.

CORVALÁN LEPE, Luis. De lo vivido y lo peleado. Memorias. Santiago: LOM Ediciones, 1997.

FURCI, Carmelo. El Partido Comunista de Chile y la vía al socialismo. Santiago: Ariadna Ediciones, 2008.

GÁRATE, Manuel. La revolución capitalista de Chile (1973-2003). Santiago: Editorial Alberto Hurtado, 2012. 
GOICOVIC, Igor. La refundación del capitalismo y la transición democrática en Chile (19732004), In: Historia Actual Online, 10, Asociación de Historia Actual/Universidad de Cádiz, Cádiz, 2006, 7-16.

HERREROS, Francisco. Del Gobierno de pueblo a la Rebelión Popular. Historia del Partido Comunista 1970-1990. Santiago: Editorial Siglo XXI, 2003.

MOULIAN, Tomás. Chile actual. Anatomía de un mito. Santiago: LOM, 1997.

MOULIAN, Tomás y TORRES, Isabel. Continuidad o cambio en la línea política del Partido Comunista de Chile. En: VARAS, Augusto; RIQUELME, Alfredo y CASALS, Marcelo (editores). El Partido Comunista en Chile. Una historia presente. Santiago: Editorial Catalonia - USACH - FLACSO, 2010, 291-326.

PÉREZ, Claudio. De la guerra contra Somoza a la guerra contra Pinochet. La experiencia internacionalista y la construcción de la Fuerza Militar propia del Partido Comunista de Chile, In: PÉREZ, Claudio y POZZI, Pablo (edits). Historia oral e historia política: Izquierda y lucha armada en América Latina, 1960-1990. Santiago. LOM Ediciones, 2012, 213-244.

PÉREZ, Claudio. Gonzalo: Militancia e internacionalismo. Una aproximación histórica al desarrollo de la Tarea Militar del Partido Comunista de Chile, In: PENSADO, Patricia (coord.). Experimentar en la Izquierda: Historias de militancias en América Latina, 19501990. CLACSO. Buenos Aires, 2013, 102-128.

PINTO, Julio. ¿Y la historia les dio la razón? El MIR en Dictadura, 1973-1981, In: VALDIVIA, Verónica; ÁLVAREZ, Rolando y PINTO, Julio. Su revolución contra nuestra revolución. Izquierdas y derechas en el Chile de Pinochet (1973-1981). Santiago: LOM, 2006, 153-205.

RIQUELME, Alfredo. Un rojo atardecer. El comunismo chileno entre dictadura y democracia. Santiago: Centro de Investigaciones Diego Barros Arana, 2009.

ROJAS, Luis. De la rebelión popular a la sublevación imaginada. Antecedentes de la Historia Política y Militar del Partido Comunista de Chile y del FPMR, 1973-1990. Santiago: LOM, 2011.

TIRONI, Eugenio. Los silencios de la revolución. Chile: la otra cara de la modernización. Santiago: Editorial Antártica, 1988.

TORO, Carlos. La Guardia muere, pero no se rinde... mierda. Memorias de Carlos Toro. Santiago: (sin editorial), 2007.

VARAS, Augusto. De la violencia aguda al registro electoral: estrategia y política de alianzas del PC, 1980-1987. En VARAS, Augusto; RIQUELME, Alfredo y CASALS, Marcelo 
(editores). El Partido Comunista en Chile. Una historia presente. Santiago: Editorial Catalonia - USACH - FLACSO, 2010, 335-347.

VENEGAS, Hernán. El Partido Comunista de Chile: desde su tradición aliancista al aislamiento político como resultado de su estrategia de Rebelión Popular de Masas. 19221989. Huelva: Universidad de Huelva, 2008 (Tesis de doctorado en Historia).

VENEGAS; Hernán. Trayectoria del Partido Comunista de Chile. De la crisis de la Unidad Popular a la política de rebelión popular de masas, In: Universum, vol 2, no. 24, Instituto de Estudios Humanísticos Juan Ignacio Molina de la Universidad de Talca. Talca, II semestre de 2009, 262-293. 